Original Article

\title{
Effects of horseback riding exercise therapy on hormone levels in elderly persons
}

\author{
Sung-Hyoun Cho, PhD ${ }^{1)}$, Jin-Woo Kim, PhD²), Seon-Rye Kim, PhD ${ }^{3)}$, Byung-Jun Cho, PhD ${ }^{4}$ * \\ 1) Department of Physical Therapy, Nambu University, Republic of Korea \\ 2) Department of Emergency Medical Technology, Daejeon Health Sciences College, Republic of Korea \\ 3) Department of Pharmacy, College of Pharmacy, Chungnam National University, Republic of Korea \\ 4) Department of Emergency Medical Technology, Kangwon National University: Kuydong Samcheok \\ City, Kangwondo 245-711, Republic of Korea
}

\begin{abstract}
Purpose] The purpose of this study was to investigate the effect of riding exercise on hormone levels in normal elderly people who were taught horseback riding for 8 weeks. [Subjects] Subjects were classified into an exercise group $(\mathrm{n}=10)$ and control group $(\mathrm{n}=10)$. [Methods] The two groups, horseback riding exercise group of 10 and control group of 10, were each tested for 15 minutes, 3 times, over 8 weeks. Post-exercise tests were implemented in both groups in the same way as pre-study tests. [Results] The horseback riding group showed a significant difference in the pre- and post-exercise serotonin and cortisol levels. Additionally, serotonin and cortisol levels showed significant differences between the two groups. [Conclusion] Serotonin and cortisol levels significantly increased in the experimental group, suggesting that horseback riding exercise is effective for improving the levels of these hormones.

Key words: Hormone, Exercise therapy, Horseback riding
\end{abstract}

(This article was submitted Jan. 30, 2015, and was accepted Apr. 16, 2015)

\section{INTRODUCTION}

Horseback riding is a treatment that stimulates a unique 3-dimensional movement by using a horse, and it is a part of special physical therapies that improve movement to control body balance ${ }^{1)}$. One of the effects of horseback riding is to transfer the 3-dimensional movement, which is very similar to pelvic tilting, to the pelvis of the person who is riding the horse ${ }^{2)}$. Riding exercise influences parts of the body that are not affected by other existing exercises, recruiting the agonistic deep muscles that contract and relax to maintain balance $^{3)}$. Riding exercise is being reviewed not only for its physical effects, but also for its social and mental effects. This is because riding involves physical interactions between patients and horses and promotes social activities among riders, who must communicate with surrounding people, including managers ${ }^{4}$. Little information exists on horseback riding as a physical therapy modality, and even less research has been conducted on whether riding exercise is beneficial in elderly persons and how this exercise affects them. This study aimed to investigate the effect of riding exercise on hormone levels in normal elderly people who were taught horseback riding for 8 weeks.

*Corresponding author. Byung-Jun Cho (E-mail: Cho6451@ gmail.com)

(C2015 The Society of Physical Therapy Science. Published by IPEC Inc. This is an open-access article distributed under the terms of the Creative Commons Attribution Non-Commercial No Derivatives (by-ncnd) License $<$ http://creativecommons.org/licenses/by-nc-nd/3.0/> .

\section{SUBJECTS AND METHODS}

This study was conducted on 20 elderly persons who each gave written informed consent for participation in the study. Subjects were divided into two groups: a horseback riding exercise group of 10 and a control group of 10 . Tests were performed on all subjects for 15 minutes, 3 times, over 8 weeks. Post-exercise tests were implemented in both groups after 8 weeks in the same way as pre-study tests. The study compared the horseback riding exercise group (age $69.53 \pm$ $3.23 \mathrm{yrs}$, height $157.60 \pm 8.73 \mathrm{~cm}$, weight $58.76 \pm 7.89 \mathrm{~kg}$, body mass index $23.64 \pm 2.27 \mathrm{~kg} / \mathrm{m}^{2}$ ) with the control group (age $69.73 \pm 3.49 \mathrm{yrs}$, height $158.47 \pm 6.76 \mathrm{~cm}$, weight 59.20 $\pm 6.66 \mathrm{~kg}$, body mass index $23.61 \pm 2.59 \mathrm{~kg} / \mathrm{m}^{2}$ ) and checked the influence of hormone levels and background EEG on the relative alpha power index. Jeju horses, which are used to give riding experiences to visitors at Rehabilitation Centeraffiliated horse-riding course, were used for this study. These horses are healthy, well-accustomed to surrounding environments, well-trained for a long time, and tame. They also have even strides. Study subjects wore safety helmets, vests, and boots. They sat on the horses and performed 5-minute exercises at a walking speed $(110 \mathrm{~m} / \mathrm{min})$. Because the subjects were all senior citizens, the study was performed at the horses' slowest walking speed. The "walk" is the slowest of horses' gaits, and is performed with a 4-foot stepping motion from the right back foot to the right front foot, and from left back foot to left front foot. During this time, an instructor led the horse by the bridle and an assistant supported the test participant, holding him or her by the leg on the right side of the horse, to facilitate the rider's movement and prevent 
Table 1. Comparison of pre-test and post-test serotonin and cortisol levels in each group (Mean \pm SD)

\begin{tabular}{cccc}
\hline & & Pre-test & Post-test \\
\hline \multirow{2}{*}{ HR } & Serotonin (ug/L) & $125.8 \pm 39.1$ & $132.4 \pm 39.1^{*}$ \\
& Cortisol (ug/dL) & $11.7 \pm 4.1$ & $11.0 \pm 3.9^{*}$ \\
CR & Serotonin (ug/L) & $124.0 \pm 36.8$ & $125.7 \pm 34.9$ \\
& Cortisol (ug/dL) & $11.5 \pm 3.3$ & $11.6 \pm 3.9$ \\
\hline
\end{tabular}

$* \mathrm{p}<0.05$

HR: horse riding group; CR: control group

falls from the horse.

Hormone analysis was implemented by Clinical Laboratory, analyzing the concentrations of serotonin and cortisol. The blood sample was collected in a serum-separating tube, which did not contain ethylenediaminetetraacetic acid, and was centrifuged at 3,000 rpm for 5 minutes. Serum serotonin analysis was conducted by high-performance liquid chromatography, and serum cortisol analysis was performed using chemiluminescent immunoassay. All experiments were reviewed and approved by the Ethics Committee of Kangwon National University. Pre-intervention and post-intervention data were examined using the paired t-test within each group of subjects and the independent t-test between the groups. The level of significance was chosen as $5 \%$ for all statistical analyses.

\section{RESULTS}

The horseback riding group showed a significant difference $(p<0.05)$ in the pre- and post-exercise levels of serotonin and cortisol (Table 1). The control group displayed increases in serotonin and cortisol levels between pre- and post-exercise tests, but the difference was not significant. The comparative tests of serotonin and cortisol levels between groups were significantly different $(p<0.05)$ (Table 2$)$.

\section{DISCUSSION}

A precedent psychological research study on horseback riding exercise revealed that it decreased depression in teenagers with emotional disorders ${ }^{5)}$. In another study, 51 children with attention deficit disorder and severe emotional disturbances participated in horseback riding exercises for 18 months, and their behavioral deficits and depression improved $^{6}$. Additionally, horseback riding exercise was reported to influence behavioral and emotional changes in children with autism ${ }^{7)}$. The exercise has also been reported to be helpful for the relief of symptoms of posttraumatic stress disorder when compared with other existing animal-assisted therapies ${ }^{8)}$. For this reason, horseback riding exercise is being reviewed not only for its physical effects, but also for its social and mental effects. We conducted a research study of older adults to evaluate their hormone levels and brain waves in relation to horseback riding exercises.

The results of the study demonstrated a significant difference between pre- and post-exercise serotonin levels in the horseback riding exercise group $(\mathrm{p}<0.05)$. This is consistent with the results of a previous study that showed that sero-
Table 2. Comparison of serotonin and cortisol levels between groups $(\mathrm{Mean} \pm \mathrm{SD})$

\begin{tabular}{lcc}
\hline Variables & HR & CR \\
\hline Serotonin & $-6.5 \pm 5.0$ & $-1.6 \pm 5.9^{*}$ \\
Cortisol & $0.6 \pm 0.6$ & $-0.1 \pm 0.9^{*}$ \\
\hline${ }^{*} \mathrm{p}<0.05$ & & \\
HR: horse riding group; CR: control group
\end{tabular}

tonin levels in a group of individuals with mental disorders increased during 12 weeks of horseback riding exercises ${ }^{9)}$. Changes in serotonin levels can differ depending on various environmental conditions, exercise level of the subject, and intensity and type of exercise. The frontal lobe controls exercise, language, intelligence, reasoning and emotion; and serotonin, through its effects on the frontal lobe, can facilitate sympathy and communication. The exact mechanism for the effect of aerobic exercise on serotonin is unknown, but it is arguable that exercise can upgrade the serotonin level, thus affecting feeling, sleep, and arousal ${ }^{10)}$.

In our study, the horseback riding exercise group showed significantly different pre- and post-exercise cortisol levels $(p<0.05)$. Cortisol levels can vary depending on exercise intensity and study conditions ${ }^{11)}$; exercise of low or moderate intensity over a short time span showed either no difference or a decrease in the cortisol level, whereas short-time highdensity exercise showed a decrease in the cortisol level ${ }^{12,13)}$. As the intensity and amount of exercise increase, the cortisol concentration in blood is thought to change.

\section{ACKNOWLEDGEMENT}

This work was supported by the National Research Foundation of Korea Grant funded by the Korean Government (NRF-120132095).

\section{REFERENCES}

1) Debuse D, Gibb C, Chandler C: Effects of hippotherapy on people with cerebral palsy from the users' perspective: a qualitative study. Physiother Theory Pract, 2009, 25: 174-192. [Medline] [CrossRef]

2) Potter JT, Evans JW, Nolt BH Jr: Therapeutic horseback riding. J Am Vet Med Assoc, 1994, 204: 131-133. [Medline]

3) Sterba JA: Does horseback riding therapy or therapist-directed hippotherapy rehabilitate children with cerebral palsy? Dev Med Child Neurol, 2007, 49: 68-73. [Medline] [CrossRef]

4) Silva e Borges MB, Werneck MJ, da Silva ML, et al.: Therapeutic effects of a horse riding simulator in children with cerebral palsy. Arq Neuropsiquiatr, 2011, 69: 799-804. [Medline] [CrossRef]

5) Ewing CA, MacDonald PM, Taylor M, et al.: Equine-facilitated learning for youths with severe emotional disorders: a quantitative and qualitative Study. Child Youth Care Forum, 2007, 36: 59-72. [CrossRef]

6) Schultz PN, Remick-Barlow GA, Robbins L: Equine-assisted psychotherapy: a mental health promotion/intervention modality for children who have experienced intra-family violence. Health Soc Care Community, 2007, 15: 265-271. [Medline] [CrossRef]

7) Wuang YP, Wang CC, Huang MH, et al.: The effectiveness of simulated developmental horse-riding program in children with autism. Adapt Phys Activ Q, 2010, 27: 113-126. [Medline]

8) MacLean B: Guest editorial: equine-assisted therapy. J Rehabil Res Dev, 2011, 48: ix-xii. [Medline] [CrossRef]

9) Lee SY, Chang SA, Chung JS, et al.: The effect of therapeutic riding on energy substrates and hormones concentration in mental retardation. J Kor Spo Soc, 2007, 25: 230-236. [CrossRef] 
10) Young SN: The clinical psychopharmacology of tryptophan. Nutr Brain, 1986, 7: 49-88.

11) Raastad T, Bjøro T, Hallén J: Hormonal responses to high- and moderateintensity strength exercise. Eur J Appl Physiol, 2000, 82: 121-128. [Medline] [CrossRef]

12) Tremblay MS, Copeland JL, Van Helder W: Effect of training status and exercise mode on endogenous steroid hormones in men. J Appl Physiol 1985, 2004, 96: 531-539. [Medline] [CrossRef]

13) Mitani Y, Doi K, Yano T, et al.: Effect of exercise using a horse-riding simulator on physical ability of frail seniors. J Phys Ther Sci, 2008, 20: 177-183. [CrossRef] 